\title{
PENGARUH RETURN ON ASSETS, DEBT TO ASSET RATIO, CURRENT RATIO, UKURAN PERUSAHAAN, DIVIDEND PAYOUT RATIO TERHADAP NILAI PERUSAHAAN MANUFAKTUR YANG TERDAFTAR DI BURSA EFEK INDONESIA
}

\author{
Rudi Darmawan \\ Program Studi Magister Manajemen Universitas Tarumanagara \\ rudi.117191039@stu.untar.ac.id \\ Carunia Mulya Firdausy \\ Program Studi Magister Manajemen Universitas Tarumanagara
}

Masuk : 07-12-2020, revisi : 20-12-2020, diterima untuk diterbitkan : 21-12-2020

\begin{abstract}
The purpose of this research is to study the influence of return on assets (ROA), debt to assets ratio (DAR), current ratio (CR), firm size, and dividend payout ratio (DPR) on the firm value measured by PBV, in manufacture companies registered on the Indonesia Stock Exchange (IDX). The number of samples of the study was 50 samples of manufacturing companies listed on the IDX and sample selection in this research using purposive sampling method, during the research period 2016 to 2018. Samples were analyzed by using the multiple regression method. The results showed that firm size and ROA has significant effects on the firm value. Whilst DPR, CR, and DAR have no significant effects on the firm value.
\end{abstract}

Keywords: Debt to Asset Ratio, Return on Assets, Dividend Payout Ratio, Firm Size, Current Ratio, Firm Value

Abstrak: Tujuan penelitian yang disajikan dalam tesis ini ialah untuk menunjukkan hasil empiris mengenai pengaruh dari return on assets (ROA), debt to asset ratio (DAR), current ratio $(\mathrm{CR})$, ukuran perusahaan dan dividend payout ratio (DPR) terhadap nilai perusahaan dimana pengukurannya dilakukan dengan rasio PBV, pada perusahaan yang bergerak dibidang manufaktur yang tercatat di Bursa Efek Indonesia (BEI). Penelitian ini menggunakan 50 sampel perusahaan manufaktur yang tercatat dalam BEI dan pemilihan sampel penelitian ini menggunakan metode purposive sampling, selama periode penelitian 2016 hingga 2018. Data dianalisis menggunakan model regresi berganda untuk menganalisis kontribusi variabel bebas yang mempengaruhi variabel terikat. Hasil empiris penelitian menjelaskan bahwa ukuran perusahaan dan ROA mempunyai pengaruh yang signifikan terhadap nilai perusahaan. DPR, CR dan DAR tidak mempunyai dampak yang signifikan terhadap nilai perusahaan.

Kata kunci: Debt to Asset Ratio, Return on Assets, Dividend Payout Ratio, Ukuran Perusahaan, Current Ratio, Nilai Perusahaan

\section{PENDAHULUAN}

Harga saham adalah gambaran dari semua keputusan finansial yang diputuskan oleh pengelola perusahaan. Keputusan finansial tersebut meliputi kebijakan pendanaan, kebijakan investasi serta keputusan dividen. Untuk itu manajemen perusahaan harus mengambil keputusan dengan penuh kehati-hatian agar kebijakan yang dipilih dapat memberikan dampak yang baik serta dapat menyebabkan terjadinya peningkatan terhadap nilai perusahaan.

Nilai perusahaan yang lebih besar bisa meningkatkan kepercayaan investor bukan hanya terhadap performa perusahaan sekarang ini, tetapi juga terhadap harapan perusahaan di masa mendatang. Bagi perusahaan yang melakukan penjualan saham kepada masyarakat, pengukuran nilai perusahaannya dapat dilihat pada nilai saham yang diperjualbelikan di Bursa Efek, semakin tinggi harga suatu saham semakin tinggi pula kemakmuran para pemegang 
saham (Sudana dalam Prasetyorini, 2013).

Terdapat beberapa penelitian dilakukan sebelumnya tentang faktor yang dapat mempengaruhi nilai perusahaan, seperti yang telah diteliti oleh Yanti dan Darmayanti (2019) yang menjelaskan bahwa ukuran perusahaan mempunyai pengaruh yang signifikan terhadap nilai perusahaan, sedangkan pada penelitian Rahmawati et al. (2015) menjelaskan bahwa ukuran perusahaan tidak mempunyai pengaruh yang signifikan terhadap nilai perusahaan.

Terdapat perbedaan penelitian yang diteliti terhadap penelitian-penelitian sebelumnya terletak pada perusahaan yang dijadikan objek penelitian dan periode penelitian. Di dalam kajian ini, digunakan data dan laporan finansial tahunan perusahaan manufaktur yang tercatat di BEI periode 2016 sampai 2018 agar diperoleh hasil penelitian yang lebih relevan dari penelitian sebelumnya. Studi ini dilakukan dengan tujuan melengkapi penelitian sebelumnya.

Tujuan studi ini ialah untuk mengkaji pengaruh return on assets, debt to asset ratio, current ratio, ukuran perusahaan dan dividend payout ratio terhadap nilai perusahaan manufaktur yang tercatat di BEI periode 2016 - 2018.

\section{TINJAUAN PUSTAKA DAN HIPOTESIS}

\section{Pengaruh Return on Assets (ROA) Terhadap Nilai Perusahaan}

Profitabilitas merupakan kemampuan perusahaan dalam menghasilkan laba bersih dari aktivitas yang dilakukan pada periode akuntansi (Prasetyorini, 2013). Profitabilitas perusahaan menunjukkan indikator efektivitas pengelolaan manajemen perusahaan dan memperlihatkan kapabilitas perusahaan dalam menghasilkan net profit dari keseluruhan asset perusahaan yang tercemin dalam nilai ROA (Return on Assets). Ketika profit suatu perusahaan meningkat, maka secara tidak langsung nilai perusahaan juga akan meningkat, hal tersebut dikarenakan pertumbuhan laba perusahaan mencerminkan performa perusahaan yang baik sehingga dapat menjadi sinyal untuk para investor yang akan menanamkan dananya di perusahaan yang bersangkutan.

Rumus Retun on Assets (ROA):

$$
R O A=\frac{\text { Net Profit }}{\text { Total Assets }}
$$

\section{Pengaruh Debt to Asset Ratio (DAR) Terhadap Nilai Perusahaan}

DAR mencerminkan seberapa besar jumlah aktiva perusahaan dibiayai oleh utang atau seberapa besar utang perusahaan dapat mempengaruhi pengelolaan aktiva perusahaan. Semakin tinggi DAR berarti semakin besar jumlah modal yang digunakan sebagai modal investasi sehingga meningkatkan harga saham perusahaan. Hal ini mencerminkan bahwa apabila perusahaan semakin banyak menggunakan hutang jangka panjang untuk membiayai aktivanya maka dapat menaikkan nilai perusahaan.

Rumus Debt to Asset Ratio (DAR):

\section{Pengaruh Current Ratio (CR) Terhadap Nilai Perusahaan}

$$
\text { Debt to Asset Ratio }=\frac{\text { Total Debt }}{\text { Total Assets }}
$$

Likuiditas merupakan kapabilitas suatu perusahaan untuk memenuhi kewajiban finansial jangka pendeknya. Perusahaan yang tingkat likuiditasnya baik mencerminkan kinerja perusahaan yang baik. Hal ini dapat menjadi nilai lebih untuk menarik investor melakukan investasi pada perusahaan. Pengukuran rasio likuiditas dapat menggunakan current ratio (CR), yang merupakan pembagian rasio aktiva lancar terhadap kewajiban lancar. Rasio lancar yang rendah biasanya dianggap menunjukkan terjadinya masalah dalam likuidasi, sebaliknya rasio lancar yang terlalu tinggi juga tidak bagus, karena menunjukkan banyaknya dana menganggur yang pada akhirnya dapat mengurangi kemampuan labaan perusahaan (Sawir, 2009, p. 10).

Rumus Current Ratio (CR):

$$
C R=\frac{\text { Total Current Assets }}{\text { Total Current Liabilities }}
$$




\section{Pengaruh Ukuran Perusahaan Terhadap Nilai Perusahaan}

Ukuran perusahaan merupakan besar kecilnya suatu perusahaan yang dapat dilihat dari tingkat penjualan, jumlah ekuitas, atau jumlah aktiva yang dimiliki oleh perusahaan tersebut (Yanti \& Darmayanti, 2019). Pantow et al. (2015) menjelaskan bahwa ukuran perusahaan mampu mempengaruhi nilai perusahaan. Semakin besar nilai ukuran suatu perusahaan maka perusahaan dianggap semakin mudah untuk mendapatkan sumber pendanaan untuk aktivitas bisnis perusahaannya. Apabila sumber dana yang diperoleh semakin baik dan semakin banyak, maka operasional perusahaan secara otomatis akan terdukung secara maksimal sehingga dapat meningkatkan harga saham perusahaan. Sehingga kesimpulan yang dapat diambil adalah bahwa ukuran perusahaan dapat mempengaruhi nilai suatu perusahaan.

Rumus Ukuran Perusahaan:

$$
\text { Ukuran Perusahaan }=\text { Ln (Total Assets) }
$$

\section{Pengaruh Dividend Payout Ratio (DPR) Terhadap Nilai Perusahaan}

Kebijakan merupakan kebijakan manajemen perusahaan dalam memutuskan besarnya pembagian hasil laba yang akan dialokasikan kepada shareholder atau pemilik saham. DPR memutuskan jumlah laba yang ditahan sebagai sumber pendanaan. Semakin besar nilai laba ditahan semakin sedikit jumlah laba yang dialokasikan untuk pembayaran dividen. Pada dasarnya, profit perusahaan dapat ditahan untuk direinvestasi atau dibagi sebagai dividen kepada pemegang saham. Jika jumlah dividen dinaikkan, arus kas juga mengalami peningkatan dan hal ini akan memberikan keuntungan bagi investor. Jika dividen tidak dinaikkan, laba ditahan yang diinvestasikan kembali dan pertumbuhan di masa depan akan mengalami penurunan, sehingga akan membuat rugi para investor. Sehingga keputusan dividen yang baik adalah dengan memaksimalkan harga saham dan menyeimbangkan kedua hal tersebut.

Rumus Dividen Payout Ratio (DPR):

$$
D P R=\frac{\text { Dividend Per Share }}{\text { Earnings Per Share }}
$$

Dari penelitian-penelitan terdahulu terdapat lima hipotesis alternatif pada penelitian ini:

$\mathrm{Ha}_{1}$ : ROA memiliki pengaruh pada nilai perusahaan pada industri manufaktur yang tercatat di BEI selama tahun 2016-2018.

$\mathrm{Ha} 2$ : DAR berpengaruh terhadap nilai perusahaan pada industri manufaktur yang tercatat di BEI selama tahun 2016-2018.

Ha3 : CR berpengaruh terhadap nilai perusahaan pada industri manufaktur yang tercatat di BEI selama tahun 2016-2018.

$\mathrm{Ha}_{4}$ : Ukuran Perusahaan berpengaruh terhadap nilai perusahaan pada industri manufaktur yang tercatat di BEI selama tahun 2016-2018.

Ha5: DPR berpengaruh terhadap nilai perusahaan pada industri manufaktur yang tercatat di BEI selama tahun 2016-2018.

\section{METODOLOGI PENELITIAN}

Populasi penelitian ini merupakan perusahaan industri manufaktur yang tercatat di BEI tahun 2016 - 2018. Jumlah populasi dalam studi ini sejumlah 50 perusahaan. Pemilihan sampel dipilih berdasarkan metode purposive sampling, yakni dibtuhkan kriteria dan kategori tertentu dalam melakukan pengambilan sampel.

Penelitian ini menggunakan sumber data sekunder dimana data diperoleh secara tidak langsung dari objek yang diteliti. Pengumpulan data ini dilakukan dengan cara mengakses situs BEI yaitu www.idx.co.id.

Variabel yang dianalisis yakni nilai perusahaan (Y) sebagai variabel dependen dan ROA (X1), DAR (X2), CR (X3), Ukuran Perusahaan (X4), dan DPR (X5) sebagai variabel independen. Secara statistik persamaan dari semua variable yang diteliti adalah sebagai berikut: $\mathrm{Y}=\ln \alpha+\beta 1 \ln \mathrm{X} 1+\beta 2 \ln \mathrm{X} 2+\beta 3 \ln \mathrm{X} 3+\beta 4 \ln \mathrm{X} 4+\beta 5 \ln \mathrm{X} 5+\varepsilon$ 
Keterangan:

Y : Nilai Perusahaan (PBV)

$\ln \alpha \quad: \quad \log$ natural konstanta

$\beta 1-\beta 5 \quad$ : Koefisien regresi linier

ln X1 : log natural Return on Assets (rasio)

ln $\mathrm{X} 2 \quad$ : $\quad \log$ natural Debt to Asset Ratio (rasio)

In X3 : log natural Current Ratio (rasio)

In X4 : $\log$ natural Ukuran Perusahaan (rasio)

ln X5 : log natural Dividen Payout Ratio (rasio)

$\varepsilon \quad$ : Koefisien Error

Metode analisis data dalam studi ini diuji dengan menggunakan aplikasi pengolahan data Statistical Package for Social Science (SPSS) versi 25.00.

\section{ANALISIS DAN BAHASAN TEMUAN}

Berdasarkan hasil penelitian diperoleh model persamaaan sebagai berikut:

PBV = -6,925 + 0,776 ROA + 0,150 DAR - 0,134 CR + 3,952 SIZE + 0,075 DPR

Dari hasil regresi berganda diatas, pengaruh dari tiap-tiap variabel bebas terhadap variabel terikat disimpulkan sebagai berikut:

a. Nilai konstanta yang diperoleh adalah sebesar $-6,925$, yang berarti apabila ROA (X1), DAR (X2), CR (X3), SIZE (X4), dan DPR (X5) sama dengan 0 (nol) maka nilai perusahaan akan mengalami penurunan sebesar 6,925 .

b. Hasil regresi variabel ROA diperoleh nilai koefisiennya sebesar 0,776, yang artinya jika dengan asumsi variabel independen tetap konstan dan variabel ROA dinaikkan satu satuan maka nilai perusahaan akan mengalami peningkatan sebesar 0,776.

c. Hasil regresi variabel DAR diperoleh nilai koefisiennya sebesar 0,150 , yang artinya jika dengan asumsi variabel independen lain konstan dan variabel DAR dinaikkan satu satuan maka nilai perusahaan akan mengalami peningkatan sebesar 0,150 .

d. Hasil regresi variabel CR diperoleh nilai koefisiennya sebesar - 0,134 , yang berarti jika dengan asumsi variabel independen lain konstan dan variabel CR dinaikkan satu satuan maka nilai perusahaan akan mengalami penurunan sebesar 0,134 .

e. Hasil regresi variabel SIZE diperoleh nilai koefisiennya sebesar 3,952, yang berarti jika dengan asumsi variabel independen lain konstan dan variabel SIZE dinaikkan satu satuan maka nilai perusahaan akan mengalami peningkatan sebesar 3,952.

f. Hasil regresi variabel DPR didapat nilai koefisiennya sebesar 0,075, yang memiliki arti jika dengan asumsi variabel independen lain konstan dan variabel DPR dinaikkan satu satuan maka nilai perusahaan akan mengalami peningkatan sebesar 0,075 .

\section{Tabel 1}

Hasil dari Uji t (t test)

Coefficients $^{\mathrm{a}}$

\begin{tabular}{|c|c|c|c|c|c|c|}
\hline \multirow[b]{2}{*}{ Mode } & & \multicolumn{2}{|c|}{ Unstandardized Coefficients } & \multirow{2}{*}{$\begin{array}{c}\begin{array}{c}\text { Standardized } \\
\text { Coefficients }\end{array} \\
\text { Beta }\end{array}$} & \multirow[b]{2}{*}{$t$} & \multirow[b]{2}{*}{ Sig. } \\
\hline & & B & Std. Error & & & \\
\hline \multirow[t]{6}{*}{1} & (Constant) & $-6,925$ & 3,143 & & $-2,204$ &, 029 \\
\hline & Transform_ROA &, 776 & ,084 &, 603 & 9,233 &, 000 \\
\hline & Transform_DAR &, 150 & ,155 &, 066 & 970 &, 334 \\
\hline & Transform_CR &,- 134 &, 090 &,- 105 & $-1,497$ & ,137 \\
\hline & Transform_SIZE & 3,952 & 1,210 &, 204 & 3,267 &, 001 \\
\hline & Transform_DPR &, 075 &, 067 &, 073 & 1,124 &, 263 \\
\hline
\end{tabular}

a. Dependent Variable: Transform_PBV

Sumber: Hasil pengolahan data SPSS IBM 25 
Jika dilihat secara bersama sama, diperoleh hasil bahwa kelima variabel independen secara bersama-sama memiliki pengaruh pada nilai perusahaan. Hal ini dapat diketahui dari tabel hasil dari uji $\mathrm{F}$ (Tabel 2).

\section{Tabel 2}

Hasil dari Uji F (F test)

ANOVA $^{\mathrm{a}}$

\begin{tabular}{|rl|r|r|r|r|r|}
\hline \multicolumn{2}{|c|}{ Model } & \multicolumn{1}{c|}{$\begin{array}{c}\text { Sum of } \\
\text { Squares }\end{array}$} & df & Mean Square & \multicolumn{1}{c|}{ F } & Sig. \\
\hline 1 & Regression & 86,357 & 5 & 17,271 & 30,822 &, $000^{\mathrm{b}}$ \\
& Residual & 80,691 & 144 &, 560 & & \\
& Total & 167,048 & 149 & & & \\
\hline
\end{tabular}

a. Dependent Variable: Transform_PBV

b. Predictors: (Constant), Transform_DPR, Transform_CR, Transform_SIZE,

Transform_ROA, Transform_DAR

Sumber: Diolah dari data penelitian.

Berdasarkan hasil dari uji koefisien determinasi maka didapat hasil $R$-squared $\left(\mathrm{R}^{2}\right)$ sebesar 0,517. Angka $\left(\mathrm{R}^{2}\right)$ yang diperoleh mendekati 0 menunjukan hubungan yang lemah. Nilai $R^{2}$ (koefisien determinasi) sebesar $51,7 \%$. Secara statistik, ini berarti besarnya variasi variabel dependen nilai perusahaan yang bisa dijelaskan oleh variasi variabel independen adalah sebesar 51,7\% sedangkan sisanya sebesar 48,3\% dijelaskan oleh faktor-faktor lain yang tidak termasuk di dalam model penelitian.

\section{KESIMPULAN DAN SARAN Kesimpulan}

Dengan melakukan uji t maka diperoleh hasil bahwa ukuran perusahaan return on assets mempunyai pengaruh signifikan serta positif pada nilai perusahaan. Debt to asset ratio dan dividen payout ratio tidak mempunyai pengaruh signifikan terhadap nilai perusahaan tetapi memiliki pengaruh yang positif. Current ratio tidak memiliki pengaruh signifikan pada nilai perusahaan tetapi mempunyai pengaruh negatif. Namun secara bersamaan semua variabel bebas yang diestimasi dalam studi ini mempunyai pengaruh yang signifikan terhadap nilai perusahaan yang tercatat di BEI.

\section{Saran}

Dari hasil studi ini, terdapat saran yang bisa diberikan yaitu, sebagai berikut:

1. Bagi perusahaan, terutama yang menjadi objek penelitian, agar dapat mempertimbangkan faktor-faktor yang mampu mengoptimalkan nilai perusahaan.

2. Bagi investor, ketika menentukan keinginan dalam melakukan investasi pada suatu perusahaan, sebaiknya tidak hanya mengandalkan pada satu faktor tertentu, namun mempertimbangkan beberapa faktor dapat mempengaruhi nilai perusahaan.

3. Bagi peneliti selanjutnya, agar penelitian ini bisa digunakan secara luas dan umum, maka diharapkan untuk dapat menggunakan subjek penelitian yang tidak hanya terbatas dalam sektor manufaktur yang tercatat di BEI, tetapi juga dari jenis sektor yang lain. Selain itu, peneliti juga bisa menambahkan periode penelitian dan beberapa variable yang dapat mempengaruhi nilai perusahaan.

\section{DAFTAR PUSTAKA}

Pantow, M. S. R., Murni, S., \& Trang, I. (2015). Analisa pertumbuhan penjualan, ukuran perusahaan, return on asset, dan struktur modal terhadap nilai perusahaan yang tercatat di indeks LQ45. Jurnal Riset Ekonomi, Manajemen, Bisnis Dan Akuntansi, 3(1), 961971. https://doi.org/10.35794/emba.v3i1.7801

Prasetyorini, B. F. (2013). Pengaruh ukuran perusahaan, leverage, price earning ratio dan profitabilitas terhadap nilai perusahaan. Jurnal Ilmu Manajemen (JIM), 1(1), 183-196. 
Rahmawati, A. D., Topowijono, \& Sulasmiyati, S. (2015). Pengaruh ukuran perusahaan, profitabilitas, struktur modal, dan keputusan investasi terhadap nilai perusahaan. Jurnal Administrasi Bisnis S1 Universitas Brawijaya, 23(2), 85999.

Sawir, A. (2009). Analisis kinerja keuangan dan perencanaan keuangan perusahaan. PT Gramedia Pustaka Utama.

Yanti, I. G. A. D. N., \& Darmayanti, N. P. A. (2019). Pengaruh profitabilitas, ukuran perusahaan, struktur modal, dan likuiditas terhadap nilai perusahaan makanan dan minuman. E-Jurnal Manajemen Universitas Udayana, 8(4), 2297-2324. https://doi.org/10.24843/ejmunud.2019.v08.i04.p15 